\title{
Huashan Rock Art: Presentation of a Chinese Cultural Heritage Site in the Absence of Tourism Infrastructure
}

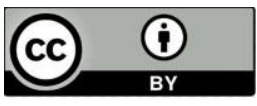

XI Qin (john.walsh2@rmit. edu.vn),Shinawatra University, Tailândia

John Walsh (john.walsh2@rmit.edu.vn),School of Business and Management, RMIT Vietnam

\section{SUMMARY}

The Huashan Rock Art site is a cultural tourism site of considerable importance in the development of domestic tourism focusing on heritage and history. As a previously peripheral part of Chinese society, Huashan has a significant role in explaining to Chinese people the extent and complexity of their history. Yet development of the research site has been hampered by the lack of tourism infrastructure (e.g. managerial capacity, accommodation, transportation, integrated services and so forth) and the private sector is not well-positioned to make up for the shortfall. The situation compares unfavourably with other destinations in neighbouring provinces. Under these circumstances, a program of qualitative research was launched using in-depth personal interviews to investigate the means by which Huashan Rock Art site is being presented and promoted currently and how can that presentation lead to an emotional and ideological response. It was found that there is some interaction between the type and nature of presentation and the success of the site in terms of destination management and this interaction is explored.

Keywords: in Portuguese, minimum 3, maximum 5, separated by commas.

\section{ABSTRACT}

The Huashan Rock Art site is a cultural tourism site of considerable importance in the development of domestic tourism focusing on heritage and history. As a previously peripheral part of Chinese society, Huashan has a significant role in explaining to Chinese people the extent and complexity of their history. Yet development of the research site has been hampered by the lack of tourism infrastructure (e.g. managerial capacity, accommodation, transportation, integrated services and so forth) and the private sector is not well-positioned to make up for the shortfall. The situation compares unfavourably with other destinations in neighbouring provinces. Under these circumstances, a program of qualitative research was launched using in-depth personal 
interviews to investigate the means by which Huashan Rock Art site is being presented and promoted currently and how can that presentation lead to an emotional and ideological response. It was found that there is some interaction between the type and nature of presentation and the success ofthe site in terms of destination management and this interaction is explored.

Keywords: China, cultural tourism, domestic tourism, Huashan Rock Art , tourism infrastructure

\section{INTRODUCTION}

The Zuojiang-Huashan rock art historical monument consists of a total of some 1900 painted characters that adorn cliffs at 30-90 m above the level of the River Ming, in Ninming Country in Guangxi province in southern China. The paintings use a combination of red ochre, blood and animal products to make a characteristic red hue for the illustrations of people, animals, ships and tools. The monument has become China's 49th UNESCO World HeritageSite (UNESCO, 2020).

The rock art is now believed to have been added between 16,000-690years before present (BP) and span a period ranging from the Warring States period to the early modern period. They were painted by people generally known as the Lao Yue, who represent a confederation of similar tribes who occupied territory from Guangxi to northern Vietnam and are associated with the international trading network centred on dong son bronze bells (Meacham, 1996). They are believed to be forerunners of Tai-speaking people such as the Zhuang, who now have their own autonomous zone in Guangxiprovince and are considered to be the largest of the 56 ethnic minority peoples in China with a population of more than 16 million people (Ministry of Foreign Affairs of the People's Republic of China, 2014).

The Lao Yue people were regarded as being different from the majority of Chinese people throughout the ages. The famed historian Sima Qian (c.145-c.86 $\mathrm{BCE})$, for example, described them as having short hair, tattooed faces and bodies, wearing garments made from plant fibres and preferring to 
live in villages, which characteristics were distinct from what he considered to be the Chinese proper (Peters, 1990).

After the victory of the Chinese Communist Party at the end of the Chinese Civil War, the Zhuang, like other ethnic minority people, were accepted as equal members of society with some different administrative procedures governing their daily lives. In general, Chinese people have notbeen encouraged to explore or express ethnic minority differences while they were involved in the transformation of society into one of equality. Outward differences such as distinctive clothing or language were not celebrated. However, since the opening of the Chinese economy to the world and the move towards a capitalist economic system some ethnic minority differences have become included in tourism attractions.

In doing so, a picturesque view of the past has been preferred to an accurate one. For example, the Village of Ethnic Minority Culture at Kunming province has people from numerous different ethnic minority groups living next to each other with one house each (Yang, 2010) and there are persistent rumours that most of the actors apparently living in these houses are in fact majority Han Chinese posing as ethnic minority people. The firedancing ritual in Lijiang City takes place every day during the tourist season instead of once a year. Costumes worn by women are sexualised irrespective of practicalityand so forth. In some cases, as in the presentation of folk dance and musicand the consumption of distinctive types of food, it is comparatively easy fortourists to understand what is being presented to them and to formulate an emotional and/or an intellectual response to it (Su, 2010). However, when the presentation is of rock art figures which bear only a passing resemblance toeveryday life, it is much more difficult for general tourists to formulate such a response and even those who are of Zhuang heritage can find it difficult to experience a genuine connection to it. This poses particular problems in tourism management and helps to create the following research questions: 
- What is the current nature of the presentation of the Huashan Rock Art landscape to tourists?

To what extent have efforts been made to present the Huashan Rock Art landscape to tourists in such a way that it helps stimulate an emotional or intellectual response?

\section{LITERATURE REVIEW}

\section{Heritage Tourism}

The Huashan Rock Art landscape may be considered to be part of the heritage tourism phenomenon. It is, in other words, "... tourism related to whatwe have invented (McCain \& Ray, 2003:713)." This statement incorporates theconcepts of both 'invention' and of 'we.' Both of these concepts have the implication of authenticity: the rock art was literally invented by its artists but has it now been invented in a new form as a tourist attraction or has its essential meaning, if any, remained the same? Similarly, who is the 'we' who are involved in the consumption of this experience? Is it necessary to be aZhuang or Chinese to be able to relate to it or understand it or is it possible for all people to be able genuinely to experience it? The nature of modern Chinese history has been to incorporate these apparently disparate elements into a mainstream feeling of unity. This inevitably adds a desirable level ofauthenticity to the experience.

This approach has only to a certain extent been used in scholarship about heritage tourism in China, which has tended to focus more on the shortcomings of the management of the site and the need to improve genuine understanding of the central features of the site (e.g. Su \& Wall, 2011). It often appears to be the case that an ideal management model is envisaged to which Chinese destination management must always be compared, which is a quest that they must certainly fail to achieve in the end (Zhang, Fyall \& Zheng, 2015). It is certainly true that any recognised pattern ofrational tourism development depends on an amalgamation of public and 
private sector leadership over a number of years that it is difficult to reproduce in the short or import without paying attention to location-specificfactors.

\section{Tourism Development}

Tourism development in the form of enhanced destination management relies upon institutional factors such as the stable and transparent allocation of resources and the fostering of genuine demand for tourism services that can be met by local providers. In many parts of East Asia, bottlenecks in thesupply of these resources and capabilities can prevent and sometimes even prevent the satisfactory development of required services (e.g. Walsh \& Apivantanaporn, 2015; Khin \& Walsh, 2019).

To these capabilities may be added the growing importance and scope of social media platforms and related forms of technology which have become increasingly omnipresent in both informing people and helping to influence their way of thinking. These technologies are now taking their place at the forefront of tourism development activities (Munar, 2012). Internet technology can incorporate elements of the past both in their own right and incontemporary re-presentations of the past, in the way that the Friendlies represented Chinese history at the Beijing Olympics of 2008. These five multi-coloured cartoons combined elements of traditional historiography, ethnic minority elements, the panda bears that have international renown and the globalisation that is symptomatic of the Olympic Games. Cui (2013:1220) argued that: "Central Television's live broadcast of the opening ceremony ofthe Beijing Olympics ... was carefully constructed as a societywide ritual to consolidate the Chinese society and instil renewed loyalty and pride into theChinese national identity."

Presentation of symbology related to Huashan Rock Art may be used in a similar method, particularly if those signs are re-presented in more user-friendly ways as the Beijing Olympics Friendlies re-presented Chinese history in a 
warm, inclusive and very open way. The extent to which this might take place is part of the current research and incorporates an element of the reimagination of the Rock Art and its place in the memory of Chinese history is one of the main issues concerned with in this paper. The nature of such modernization of traditional themes has been lightly addressed in tourism literature, mostly with a negative perspective (Su \& Teo, 2008; Evans, 2000) or else focus almost entirely on technical issues (e.g. Ma, 2008).

\section{The Research Site}

Guangxi province is located on the southeast coast of China, bordered by Guangdong province to the east, Hunan and Guizhou to the north, Yunnan to the west and Vietnam to the southwest. It had a gross provincial product(GPP) of RMB 2,035.25 billion, which is higher than Yunnan $(1,788.11)$ and Guizhou $(1,480.65)$ but lower than Hunan $(3,642.58)$ and far behind Guangdong $(9,727.78)$ (Statista, 2020). Its major industries include sugarcane and food processing, nonferrous metals, automobiles and heavy mining machinery. Its exports (RMB 217.6 bn) exceed its imports (RMB 193.1 bn) and both are dominated by primary goods and components (Department of Guangxi Zhuang Autonomous Region, n.d.). As a coastal province, Guangxi has a special economic zone centred on the Beibu Gulf and incorporates the cities of Nanning, Yulin, Chongzuo, Fanchenggang, Qinzhou and Beihai. Aspart of this project, the ports of Fangcheng, Qinzhou and Beihai are to be merged under the title Guangxi Beibu Gulf Port Group (People's Government of Guangxi Zhuang Autonomous Region, 2018). However, there have beensome reports that progress in this respect has been slow.

There is a growing trend of inequality in the province, which is being intensified by spatiality, investment and industrialisation. Since ethnicity and geographic location are correlated, then ethnicity is linked with growing levels of inequality (Dai et al., 2018). Nevertheless, as a border province with ahigh proportion of ethnic minority people, Guangxi has long suffered from 
poverty, especially rural poverty, which has nevertheless been greatly diminished in recent years, with the rural poverty rate having been reducedfrom $70 \%$ in 1978 to $5.9 \%$ at the end of 2017 and life expectancy having risenfrom 60 in 1963 to 77 in 2017 (Xinhua, 2018).

Tourism has become a significant industry in Guangxi province and there were 288.9 million workers in 2018 who spent a total of RMB 762 bn. Most were younger tourists who travelled by train from neighbouring provinces Guangdong and Hunan and also from Zhejiang. The Winter Tourism in Guangxi campaign has been deemed to be successful with an increase of more than $22.5 \%$ to 6.1 million visitors between December-January. Overall, most visitors went to Nanning, Guilin, Liuzhou and Beihai (People's Government of Guangxi Zhuang Autonomous Region, 2019). The presence ofa range of different ethnic groups in the province has led to the promotion of a concomitant list of tourist attraction and events. Many of these are linked to specific ethnic groups, such as the Sanyuesan Festival of the Zhuang people(which is also celebrated by other groups), the Lusheng and Horse-Fighting Festival of the Miao people. There is scope for further coordination of these sites as complementary activities in an integrated tourism programme.

\section{METHODOLOGY}

This project features a qualitative research design centred on in-depth personal interviews combined with personal observation and the analysis of secondary data. The principal researcher has been involved in personal observation of a number of tourist sites in Guangxi province and has conducted a wide range of informal interviews during that time. Research for this paper was conducted in the first quarter of 2020. These have been supplemented by more formal interviews in the case of specific research projects and the papers derived from them. Observations were captured in a research journal together with other relevant data (i.e. secondary data, observations and informal qualitative interactions) that might impact uponthe opinions and discourse of interlocutors. For formal interviews, a semi- 
structured questionnaire was created which outlines question areas for each informant but which permitted the conversation to be diverted towards areas that were of interest to the informant and about which $\mathrm{s} /$ he had useful information. Interviews were recorded for future transcription and analysis using a well-known statistical software tool.

It might be noted that, in this context, formal interviewing for the current paper took place during restrictions on movement enforced by the state in the attempt to defeat the coronavirus pandemic, which was still emerging as a global phenomenon during the majority of this period. As a result, some of Bourdieu's (1972) prescriptions for analysing individuals within the context of their everyday habitus have been unavoidably broken. The difficulties this implies have been addressed by keeping in mind Lefebvre's (2014) advice on the Critique of Everyday Life that "... it begins by establishing dialectical links, reciprocities and implications rather than an unrelated hierarchy (e279/805)." By doing so, it is hoped that useful but mundane observations will not be ignored but, instead, snagged in the network of dialectical relationships. This has been conducted in the spirit of triangulation, one of the principles of social science research that aims to cater for the vagaries of the human experience: "Multiple and independent measures, if they reach the same conclusions, provide a more certain portrayal of the [explored] phenomena(Jick, 1979:602)."

That understanding has informed the approach employed here in that a database was created to host the ethnographic observations and secondaryliterature together with the 22 formal interviews conducted for this project. These interviews represent a portion of the interviews conducted over several years as part of an extensive investigation of aspects of domestic tourism inChina. For this paper, the interview transcripts and relevant secondary literature were isolated for focused analysis. The contents of the database have been subjected to a recognised form of content analysis with a view to 
understanding both the changing nature of domestic Chinese tourism and the ways it interacts with the kind of heritage tourism analysed in this paper.

The formal interviews were conducted with a range of public and private sector experts with an interest in domestic tourism, together with academics skilled in this area. Since face-to-face interviews were not possible under lockdown conditions, interviews were conducted via iterative email conversations, which facilitated the recording of transcripts although at the cost of the loss of some spontaneity. The difficulty in probing comments orlacunae in direct conversation is compensated for to some extent by the increased ability of both respondents and interviewer to gather their thoughts and frame questions and answers deliberatively (questionable comments or partly-answered questions were followed up for greater clarity). In any case, this method has, as mentioned above, benefited from the application of triangulation in order to enhance reliability.

Original research was conducted in Chinese, sometimes using local or provincial dialects, although it has been interpreted into English for the purpose of this paper. Research in this and related areas is continuing.

\section{FINDINGS}

Content analysis of the collected interview transcripts supplemented by the other contents of the research database yielded findings in the following areas: government policy issues; provincial level issues; specific site issues; thenature of private sector involvement and suggestions for improvements. Theseissues will now be dealt with sequentially.

\section{Government Policy Issues}

While the national government has been active in formulating overall policyfor the promotion of domestic and international tourism, this has not yet been matched by the kind of integrated development of policies and resources at 
different organizational levels known as 'joined up thinking.' As one eminent academic explained in one of the interviews:

"The most important role of the government is to create conditions for the development of tourism, especially the hardware environment and software environment such as policies and regulations. It must also conform to the actual situation of tourism and create a good service and investment environment."

It is in the issue of 'actual situation of tourism' that respondents often focused their comments. While the central government has formulated national policy, tourist resorts are more commonly better approached through local, provincial or regional levels and, also, might not fall conveniently into one of the pre-designated categories which it might be considered appropriate to allocate them. The Huashan Rock Art phenomenon, for example, appears tobe a form of historic tourism but also has a clear ethnic component and, by virtue of the fact that it can only really be approached by river as a touristexperience, is also part of an integrated cruise of tour experience. These particular local characteristics are quite independent of the World Cultural Heritage (WCH) site designation and mean that the attempt to treat all WCHsites with the same set of policy guidelines will prove to be problematic. This aligns with the observation of another respondent, that the government's role "... is not just to issue documents for everyone to develop the cultural tourism industry but to analyse the cultural tourism industry in different places anddevelop a good supervision role." That is, the relationship between policy and research site should become more sophisticated (or always to have been more sophisticated) in not being just prescriptive but to be able to supervise effectively without constricting to a single mode of operation.

A separate issue, although related to the above, which will be explored further in the following section, concerns inter-provincial relations and central-provincial relations. From an historical basis, it became familiar to case inter- 
provincial relations as competitive and, from the nature of globalised economic systems has added a new layer to this basic relationship that is certainly applicable to the consideration of tourism: "Since the 2000s, economic development and agglomeration in China have created more scope of and need for collaboration." This collaboration is valued at both local and central levels of government and adds a different perspective to the desire for decentralisation ( $\mathrm{Li} \& \mathrm{Wu}, 2012$ ).

At the simplest and most obvious level, it is clear that coherent multi-site tourism activities are unlikely to follow geographical borders, so cross-border relationships are unavoidable. However, there is a deeper level of collaboration possible in, for example, Southeastern China presenting the incorporation of ethnic minority people into the state in a way that recognises not just their importance as citizens and servants of the state but also provides for the dignity of the communities involved. This is a manifestation of a wider point that coherent socio-economic areas can develop across time and diverge from national borders which, from that socio-economic perspective, might have once been more important that they now would be if the regions could be given fuller expression.

\section{Provincial Level Issues}

As the previous section has shown, there is a complex set of relationships between the central government and provincial levels of government. This involves both competition and collaboration. However, in the research, respondents were most commonly exercised by the perceived failures of the provincial government in creating an effective vision and plan for tourism development but, more deeply, in developing provincial-level facilities to the degree required, it is believed, to compete effectively in the globalised contemporary world. This became evident not just in the shortcomings of Guangxi's government but in what was thought to be the superior 
performance of neighbour-competitors such as Guizhou (as expressed by anacademic respondent):

"It is recommended to learn from Guizhou, etc., to learn about Guizhou's bold innovation, emancipating the mind, and flexible policies ... preferential land use policies and tax policies got tourism investors."

Since it was generally agreed that management capacity and resources remained limited across the country (which might reflect something of a national characteristic), it was believed that success at the provincial level should not only be replicated elsewhere but that it would be possible to replicate it. That is, success in policy development depended primarily on deft resource allocation and coherent thinking. As the same respondent concluded "... unified planning and policy of the provincial government are very important."

The actual nature of what the provincial government could provide, on the other hand, did tend to vary. One member of the private sector felt that the scope of official policy was very wide:

"Guangxi's cultural tourism industry has unlimited resources so it should adapt to local conditions, do a good job of cultural tourism infrastructure, promote the optimisation of scenic spots, and carry out entertainment programs based on local customs and practices, such as stage performances with cultural creations and experiential summer camps and parent-child activities."

Here, the respondent, who is not alone not just in this cohort of respondentsbut also in a wider cross-section of the commercial class, in believing that it is government which should be providing or at least making possible these facilities and resources, with the private sector inserting itself in the process at a latter date. Another respondent who led a tourism and communication company, also believed that it was the provincial government which shouldbe providing "... cruise ships ... and night tour experiences." Other 
respondents took a perspective at a slightly higher level, focusing on the shared resources that can make the tourism experience invisible - that is, the potential for shared travel cards, travel exemptions and so forth. However, this is still an area that, in other societies, would be considered primarily the preserve of the private sector.

On a related note, it was notable that a number of respondents included in the discussion of Huashan Rock Art and of related regional tourist sites of the signs of national development in the global context. In particular, the use of the terms 'One Belt and Road' and 'Silk Road' suggest that tourism, perhaps as one aspect of the larger context of China in the world, is another arena in which the country and its people are required to compete with the other nations of the world and to demonstrate, repeatedly and perhaps endlessly, that the local context is at least the equivalent to the international one, whether that is imagined or not. This is, to some extent, what Anderson (1998) meant by the spectre of comparisons, which is a double-edged sword in thatit may be used to hide what is done in the domestic realm while at the sametime attempting to hold it up to the international level.

A final point in this regard is rather more prosaic in that it focuses on apparent failings by the provincial level of government in areas which are widely regarded as being within their bailiwick. This includes complaints about thelack of integrative transportation infrastructure, the slow pace of development of the port project and hence connectivity to the international economy and the general lack of progress compared with other provinces. Some of the comments made in this connection are rather beyond the scopeof the paper but they do appear to show that people tend to consider this tobe a subject which is considered on a holistic basis.

\section{Site Level Issues}

The first issue to be considered in this section is the nature of marketing andpublicity in support of the Huashan Rock Art site and, in general, respondents 
were quite enthusiastic about the progress made in this area. It is evident that a considerable amount of such advertising has taken place in the past and, also, in the present and this includes those channels which have been found to be popular and successful with Chinese tourists. These channels are, increasingly, online media in nature (Xi, Sawagvudcharee \& Walsh, 2019). Generally, respondents felt there was scope to enhance the knowledge of the local region, promotion of the values of the Zhuang people andcelebration of its achievements. However, it is not clear that these sentiments will always be successful in the context of resort development and management. As one academic respondent observed:

"If the cultural tourism is done well, it will be poetic and show the scenes from a distance. The natural landscape of Huashan is to be protected and the cultural connotation is in the surroundings."

While this is a rational approach to the situation and it corresponds to the changing understanding of the nature of the contemporary tourist experience, it does not chime well with the actual logistics of the tourism industry, with its distribution and coordination and, in the context of Chinesetourists, the quality and extent of the catering. This point is worth exploringfurther. It was noted by several respondents that the nature of tourism has been changing and should now be regarded in terms of the experiences thatcan be enjoyed and recalled rather than, as was previously the case, as a series of locations and events to be ticked off as they are encountered. This change has implications for all aspects of the tourist development activities currently taking place, from promotion to experience to post-experience dissemination of information. However, this should not mean that a gap should be allowed to develop between what it is intended that tourists will be provided with in the future and what the current generation of tourists currently expects and desires. In other words, there is a need for the management of expectations during a period of transition so that needs gaps do not emerge during the press. 
In response to questions about how the research site could be improved both in terms of providing customer satisfaction to tourists and in terms of explaining the historical context of the site, respondents spoke about the need to improve the understanding of the context of the research site, since this is not clear even to people familiar with the Zhuang culture. The type ofcontext involved emerged from additional internet resources up to the provision of a museum, with practical workshops and short-term training courses. More respondents favoured a middle course in which tourists would be provided with additional information prior to and during their tourism experience with effort expended o provide a physical trace of the visit (i.e. atake-home object) as well as to match the cultural background with the actual experience of travelling to and participating in the cruise. In general, it was considered that the destination management should focus on appropriate thematic content. Use of the popular online social media such as Weibo and Wechat was also commonly recommended.

\section{Private Sector Involvement}

Many respondents spoke about the need to promote interactivity in the presentation of Huashan Rock Art and related sites, while focusing on the need to be responsive to the interests and desires of current and potential customers. This leads to a consideration of the role of the private sector in the provision of tourism services, since it is usually the case that private sectororganizations have a more direct incentive to be responsive to customer demand. This area also led to the absence of involvement of the private sector and, further, a reduced level of consideration that the private sectoractually could have such a role. Many Chinese respondents, in common with respondents from other East Asian countries and elsewhere, look first to the public sector to supply all organizational needs and rarely include private sector individuals or companies in the planning process. In part, this is because of the potential damage to cultural artifacts resulting from over- exploitation: 
"... we must prevent excessive participation of tourists and the impact of foreign cultures. The traditional customs of Lugu Lake gradually changed during the development of tourism (academic respondent)."

This is a common fear, since the overuse of tourism resources has been observed just about everywhere that a tourism industry has been developed in earnest. It has, for example, been seen in the eastern half of nearby Hainan Island and there are fears it could spread to Zhuang region fishing villages (Xinhua, 2015). There is also the danger that untrammeled private sector tourism development might lead to the maldevelopment of cultural traditions if they are just chasing the money:

"Cultural performances in tourism are sometimes incomplete and utilitarian.

Cultural tourism relies on culture, but the commercial nature of the tourism industry will bias the line of cultural heritage (ibid.)."

As noted elsewhere, this is a phenomenon that has certainly been found elsewhere in China, where tourism development has led to the misrepresentation of cultural practices for the sake of the convenience of tourists, objectification of participants, normalisation of unusual tastes andpractices and so forth. Respondents who were concerned about those possibilities tended to look to state regulation and supervision as the best means of preventing it. Nevertheless, there was also expression of the fear that, unless preserved, traditional cultures might disappear altogether:

"Modern civilisation has expanded at an alarming rate and the living space of traditional culture has shrunk. The development of tourism and cultural industries may be to protect traditional and heritage culture (academic respondent)."

However, there were more positive views of the possibilities if the private sector, in some cases, in fact, because of the failings of some aspects of thesame sector "... administrative power is too large and government officials themselves are not very professional ... [leading to] ... serious homogeneity 
and reduced authenticity experience (academic respondent)." As mentioned above, comments such as these were also sometimes accompanied by disparaging remarks about local officials compared with those of neighbouring provinces. However, members of the private sector itself were better informed about the role that commerce has played in thedevelopment of the sector over recent years:

"Huashan Rock Art was taken over by China Tourism Group in November 2018 and it has become one of the more important scenicareas operated by Hong Kong China Travel Service. It also started topromote other activities. The first event was the 60th anniversary of the founding of Guangxi and was the first large-scale themed events. The first Huashan Yuren Temple Fair was in the Spring Festival in 2019. In addition, it created a series of thematic activities such as the March $3^{\text {rd }}$ Huashan celebration, Huashan Carnival, Huashan Rock Painting Culture and Art Festival, Huashan Gepo Festival and, also, launched the Huashan Research Tour, the Huashan Little Pan Fan Rice and the firstindependent brown sugar brand of Lue Yuewong (private sector respondent)."

These events have been promoted by local, regional and national news media such as CCTV News, Guangxi News, Chongzuo News and others. Although there is a range of different activities, sites and festivals organized within the same region, there is little sense to date that they are being managed coherently or according to an overall plan that would maximise the number of tourists and their expenditure while travelling there. Instead, it appears that the various different projects are being put forward independently with only a limited amount of public sector support to knit them together as takes place elsewhere in the world and that the ability of the private sector companies present is not yet sufficiently developed to create and foster large-scale networks and partnerships with public sector bodies. 


\section{Research Questions}

Qualitative research operates on the basis of data preceding theory, by which the researcher identifies the phenomenon, which is the issue of interest, before then discovering what can be learned about it through the use of, in this case, indepth personal interviews. The eclectic assemblage of data is then interrogated with a view to identifying what patterns, theories or crystallisations of meaning might be found. However, while this approach has been followed here, it is also necessary to answer the research questions which helped launch the consideration of the phenomenon in the first place.This is attempted in the current section.

The first question concerned the current nature of the presentation of the Huashan Rock Art landscape to tourists. This framing of the question borrows from the landscape theory that attempts to understand how aggregation will contribute towards alignments among actors and, hence, how similar or congruent elements of the research site will be viewed as proximate and how, accordingly, those deemed dissimilar will be considered to be increasingly distant from each other. In this case, the nature of similarity is thatof a sense of social cohesion (including Chinese and non-Chinese but peripheral to being Chinese) arising from joint ownership of historical artefacts that unite people and place through the inscribing of human meaning on the physical landscape. The social relations of the Lao Yue people have becomeone with the land where they lived and this land has now been incorporated into Chinese society as the Zhuang people have become Chinese through the voluntary and revolutionary actions of the Chinese people. However, from a commercial perspective, it is unfortunately the case that these congruentelements are not united with the tourism infrastructure of transportation, accommodation, food and beverages and so forth. The role of the public- private intersection is to try to narrow the distance between the two divergent elements. 
The second question concerned efforts that have been made to present theHuashan Rock Art landscape to tourists in such a way that it helps stimulatean emotional or intellectual response InIt is evident from the preceding answer that a coherent meaning has been obtained for the central issue of the Rock Art site and this this inherently contains within itself an emotional as well as intellectual and ideological components. As a result, destination managers have a clear direction when it comes to seeking to direct the public in the desired direction. Of course, more needs to be done to bring out the variety of meanings that are possible and to unite them with the concrete needs of tourism that contemporary tourists demonstrate. An integrated and interpretative communication plan will be one important aspect of moving forwards in this case.

\section{DISCUSSION}

Theories of tourism development commonly focus on the combination of economic, social, cultural and environmental impacts upon potential or actual tourism sites as a means of determining the extent of community support for such a site (e.g. Yoon, Gursoy \& Chen, 2001). Yet this approachassumes a sense of agency on behalf of local communities that is misplacedin analysis of political regimes such as that of China, where decisions about resource allocation and regional economic development may be made at quite a distant level. In these cases, tourism development is more of a supply-led phenomenon that it is a demand-led one. Relevant stakeholders will identify possible sites which have aesthetic, ethnographic or historical interest and then seek to elevate those to national and international prominence. Since the private sector is only involved in this process to a limited extent - in the case of Huashan rock art because private sector organizations are nascent in nature and, hence, limited in capacity - the demand aspect of the site is rarely evaluated properly and this is likely to result in the misallocation of resources in terms of efficiency. Since there is, it has been widely argued (e.g. Font \& Ahjem, 1999) a contradiction between the goals 
of public and private sector approaches to tourism development, thedominance of the former over the latter will prevent over-exploitation of theresource but will see under-utilisation of its commercial benefits.

Although Chinese tourists have become very diverse in terms of characteristics as their experience and knowledge have increased, it remains true both that in addition to an interest in the natural world and historical features they are concerned with receiving proper value for money (Truong \& King, 2009) and that they wish to have opportunities to spend money and enjoy experiences that will form memories and might be used as a form of social capital. Some research indicates a link between tourism-derived memories and the formation of social capital (Mura \& Tavakoli, 2014). An absence or deficiency in the memory creation process that leads to such capital formation can quickly be ossified if not properly address and, thus, lead to a widespread set of assumptions about domestic tourism which canbe spread to subsequent generations of potential travellers.

The representation of tourism sites through popular mass and social media is an important component part of the way that the population overall will view the nature of Chinese domestic tourist sites. If public sector interests dominate the presentations then not only will this feed into people's expectations of the nature of the tourism experience to be had there but, also, it will reinforce expectations held by all stakeholders that the research site involved will be maintained in a static rather than a dynamic mode. While the concern felt by public sector organizations with the possible degradation of the range of experiences that they might desire is likely to be frustrated. This can become a significant discernible to travel if, as in the case of Huashan Rock Art, the experience involves a lengthy cruise which threatens not to involve the kinds of fun-based activities such cruises would be expected to exhibit.

The nature of tourism in contemporary China should be recognised as a specific phenomenon rooted in the nature of daily life. As Lefebvre observes: 
"... with its fragmentation of labour, modern industrial civilization creates both a general need for leisure and differentiated concrete needs within that general framework (emphasis in original) (2014: 19/1025. )." In addition to the desire for a holiday, a rest and the recreation of social relations necessary sothat productive work can be resumed, in other words, it is necessary for the Chinese consumer to receive some means of validation of the nature of contemporary society. Achieving the level of rapid economic that has been managed in China has required considerable levels of sacrifice by many members of society in different ways and there is a role for tourism in providingjustification for that sacrifice. One aspect of this is appropriate respect and interest in the past of the country and, for the concrete needs, the addition of a good lunch to share with family and friends. This paper reports on research that has the potential to contribute to the dual needs of tourism in this respectbut it has not yet reached that potential.

The goal that it should be attempted to achieve in this respect is one of responsible geotourism, which is "... designed to improve the quality of life for the host and the quality of experience for the tourist (Robertson, 2015)." Achieving this requires the creation and implementation of a detailed interpretive plan which incorporates a variety of forms of discourse from all relevant stakeholders. In some cases, there will need to be some education of stakeholders so that they will be capable of and willing to contribute their informed views for this purpose. This approach has implications in several aspects for the ways in which policy is made in China.

\section{CONCLUSION}

This paper reports on research conducted at the Huashan Rock Art tourist site with a view to understanding the nature and potential of this place as a destination for further development. Qualitative research in the form of faceto-face interviews was the principal means of investigation, together with some ethnographic observation and analysis of secondary literature. This form 
of research is vulnerable to the charge of homogeneity of respondents and partial understanding of phenomena which is not then tested by quantitative means. However, this is a method that has been successfully used in otherliterature in this subject (e.g. Xi et al., 2019) which has been recognised as providing a valid understanding of the subject.

The Huashan site is one of a cluster of different sites, festivals and activities which take place approximately in the same region and it is hoped that, in due course, greater levels of co-ordination will be organized to bring these diverse sites together in ways which have meaning and value for tourists and provide a memorably good experience that will also be profitable and sustainable for onsite stakeholders. Further research on a longitudinal basis will help to determine whether this will in fact take place.

Ancient rock art is unlikely ever to become one of the most popular destinations for tourists, whether they are domestic or international in origin. To become successful, the site will need to be embedded in networks and partnerships with other stakeholders and activities which would complement the nature of the original site. As contemporary society develops, the needsand demands of tourists will also develop and what they require of the mementos of the past will continually change to reflect their changing relationship with society as mediated by their work and the civic duties required of them.

\section{REFERENCES}

Anderson, P. (1998). The spectre of comparisons: Politics, culture and the nation. London and New York, NY: Verso.

Bourdieu, P. (1972). Outline of a theory of practice. Cambridge: Cambridge University Press, translated by Richard Nice. 
Cui, X. (2013). Media events are still alive: The opening ceremony of the Beijing Olympics as a media ritual, International Journal of Communication, 7, 122035.

Dai, Q., Xinyue, Y., Yehua, D.W., Yuemin, N. and Sheng D. (2018), Geography, ethnicity and regional inequality in Guangxi Zhuang Autonomous Region, China, Applied Spatial Analysis and Policy, 11, 557-80.

Department of Guangxi Zhuang Autonomous Region (n.d.), available at: http://www.gxswt.gov.cn (in Chinese).

Evans, G. (2000), Transformation of Jinghong, Xishuangbanna, PRC, in G. Evans, C. Hutton and K.K. Eng (eds.), Where China meets Southeast Asia, New York, NY: Palgrave Macmillan, 162-82.

Font, X. and Ahjem, T.E. (1999), Searching for a balance in tourism development strategies, International Journal of Contemporary Hospitality Management, $11(2 / 3), 73-7$.

Jick, T.D. (1979), Mixing qualitative and quantitative methods: Triangulation in action, Administrative Science Quarterly, 24(4), 602-11.

Khin, K.Z. and Walsh, J. (2019), Achieving sustainable community-based tourism in rural Myanmar: The case of River Ayeyarwaddy dolphin tourism, Zagreb International Review of Economics and Business, 22(.2), 95-109, doi: https://doi.org/10.2478/zireb-2019-0022, available at: https://hrcak.srce.hr/228942.

Lefebvre, H. (2014), Critique of everyday life, London and New York, NY:Verso, (e-book), translated by Gregory Elliott.

$\mathrm{Li}, \mathrm{Y}$. and $\mathrm{Wu}, \mathrm{F}$. (2012), The transformation of regional governance in China: The rescaling of statehood, Progress in Planning, 78(2), 55-79.

Ma, J.-G. (2008), An empirical study on tourism development in ethnic minority village, Commercial Research, 6. 
McCain, G. Ray, N.M., (2003), Legacy tourism: The search for personal meaning in 'heritage trends,' Tourism Management, 24(6), 713-7.

Meacham, W. (1996), Defining the hundred Yue, Bulletin of the Indo-Pacific Prehistory Association, 15, 93-100.

Ministry of Foreign Affairs of the People's Republic of China (2014), The Zhuang ethnic minority, available at: https://www.fmprc.gov.cn/mfa eng/ljzg 665465/3584 665493/t17927.shtml.

Munar, A.M. (2012), Social media strategies and destination management, Scandinavian Journal of Hospitality and Tourism, 12(2), 101-20.

Mura, P. and Tavakoli, R. (2014), Tourism and social capital in Malaysia, Current Issues in Tourism, 17(1), 28-45.

People's Government of Guangxi Zhuang Autonomous Region (2018), Beibu Gulf Port Group, available at: en-gxzf.gov.cn/2018-08/21/c_264859.htm.

People's Government of Guangxi Zhuang Autonomous Region (2019), Guangxi receives over $288.86 \mathrm{~m}$ tourists in 2018, available at: en.gxzf.gov.cn/201901/29/c_331744.htm.

Peters, H. (1990), Tattooed faces and stilt houses: Who were the ancient Yue? Sino-Platonic Papers, 17, available sinoplatonic.org/complete/spp017_yue.pdf.

Robertson, M.H. (2015), Heritage interpretation, place branding and experiential marketing in the destination management of geotourism sites, Translation Spaces, $4(2), 289-309$.

Statista (2020), Gross domestic product (GDP) of China in 2018, by region, available at: www.statista.com/statistics/278557/gdp-of-china-by-region/.

Su, M.M. and Wall, G. (2011), Chinese research on world heritage tourism, Asia Pacific Journal of Tourism Research, 16(1), 75-88. 
Su, X. (2010), The imagination of place and tourism consumption: A case study of Lijiang ancient town, China, Tourism Geographies, 12(3), 412-34.

Su, X. and Teo, P. (2008), Tourism politics in Lijiang, China: An analysis of state and local interactions in tourism development, Tourism Geographies: An International Journal of Tourism Space, Place and Environment, 10(2), 150-68.

Truong, T.H. and King, B. (2009), An evaluation of satisfaction levels among Chinese tourists in Vietnam, International Journal of Tourism Research, 11, 52135.

UNESCO (2020), Zuojiang Huashan rock art cultural landscape, available at: https://whc.unesco.org/en/list/1508/.

Walsh, J. and Apivantanaporn, T. (2015), Destination management of smallislands: The case of Koh Mak, Acta Universitatis Danubius Oeconomica, 11(3),172-96.

Xinhua (2018), Backgrounder: Guangxi in a statistical nutshell - Population and society, Xinhuanet, available at: www.xinhuanet.com/english/201812/09/c 137661448.htm.

Xinhua (2015), Overexploitation, pollution threaten China's coasts, available at: www.china.org.cn/environment/2015-06/08/content 35771951.htm.

Xi, Q., Sawagvudhcaree, O. and Walsh, J. (2019), Information sources and domestic tourism at Sanyuesan festival, China, International Business Research, 12(8), 23-30, doi:10.5539/ibr.v12n8p23.

Yang, L. (2010), Managerial perceptions of an ethnic theme park: Yunnan ethnic folk villages, China, International Journal of Tourism Anthropology, 1(1), 35-54, doi: https://doi.org/10.1504/IJTA.2010.036845.

Yoon, Y., Gursoy, D. and Chen, J.S. (2001), Validating a tourism development theory with structural equation modelling, Tourism Management, 22(4), 36372. 
Zhang, C., Fyall, A. and Zheng, Y. (2015), Heritage and tourism conflict within world heritage sites in China: A longitudinal study, Current Issues in Tourism, $18(2), 110-36$. 